\title{
Microfascismos EM NÓS: PRÁTICAS DE EXCEÇÃO NO CONTEMPORÂNEO
}

\author{
Tania Mara Galli Fonseca* \\ Andresa Ribeiro Thomazoni** \\ Luis Artur Costa*** \\ Vera Lúcia Inácio de Souza ${ }^{* * * *}$ \\ Vivian da Silva Lockmann ${ }^{* * * *}$
}

Resumo

Este artigo busca traçar um olhar sobre as práticas de exceção na contemporaneidade. Interessa-nos colocar uma lente nesse cenário em que a vida biopolítica foi presa nas tramas da lei, nas transversalidades dos poderes e que acaba por constituir a vida nua. Deste modo, tomaremos como emblema dessa questão o início da organização dos manicômios no Brasil e o campo de concentração nazista para pensarmos a constituição dessas fascistas práticas de exceção na modernidade e sua ruptura-continuidade no contemporâneo. Microfascismos em nós - práticas de exceção no contemporâneo - refere-se ao hoje de

* Psicóloga; Professora titular do Instituto de Psicologia da Universidade Federal do Rio Grande do Sul (UFRGS); Docente pesquisadora dos programas de pós-graduação em Psicologia Social e Institucional e Informática na Educação/UFRGS.

** Psicóloga e mestranda do Programa de Pós-Graduação em Psicologia Social e Institucional da Universidade Federal do Rio Grande do Sul (UFRGS); Bolsista Capes.

*** Mestre em Psicologia Social e Institucional pela Universidade Federal do Rio Grande do Sul (UFRGS); Doutorando do Programa de Pós-Graduação em Informática na Educação UFRGS; Bolsista CAPES.

**** Graduanda em Psicologia da Universidade Federal do Rio Grande do Sul (UFRGS); Bolsista de extensão do projeto intitulado "Rizomas da Loucura: o acervo da Oficina de Criatividade do Hospital Psiquiátrico São Pedro (HPSP)”.

***** Graduanda em Artes Visuais da Universidade Federal do Rio Grande do Sul (UFRGS); Bolsista de Iniciação Científica BIC/ UFRGS. 
nossas atitudes que podem assumir um viés no qual o outro, como diferença, é visto como ameaça e, assim, evitado. Não enclausuramos o outro em muros limites, porém o ignoramos e não nos deixamos afetar por ele no nosso cotidiano. Utilizar a concepção de uma vida imanente pode nos ajudar a ultrapassar as transcendências microfascistas dos fragmentários estados de exceção atuais e problematizar o campo dos direitos humanos, não para sua dissolução, mas para abri-lo à indeterminação dos acontecimentos.

Palavras-chaves: biopolítica; práticas de exceção; direitos humanos.

\section{Abstract}

\section{MICROFASCISM IN US: PRACTICES OF EXCEPTION IN CONTEMPORANEITY}

This article aims to analyze the practices of exception in contemporaneity. We are interested in examining the scenario in which the biopolitic life is arrested in the frame of law, in the transversality of powers, constituting ultimately the bare life. We will take the early organization of asylums in Brazil and the Nazi concentration camps as emblems of this issue, in order to analyze the formation of these fascist practices of exception in modernity and its ruptures as well as its continuity in contemporaneity. Microfascism in us - practices of exception in contemporaneity - refers to our current attitudes that may lead to situations in which the other, as difference, is seen as a threat and therefore avoided. We do not enclosure the other within limiting walls, but we disregard him and do not let our daily lives be affected by him. Using the concept of an immanent life can help us overcome the microfascist transcendences of today's fragmentary states of exception, and discuss the field of human rights, not to dissolve it, but to open it to the indeterminacy of events.

Keywords: biopolitics; practices of exception; human rights.

"Uma parte da nossa existência está nas almas de quem se aproxima de nós; por isso, não é humana a experiência de quem viveu dias nos quais o homem foi apenas uma coisa ante os olhos de outro homem...”.

(Levi, 1988: 173)

\section{INTRODUÇÃO}

Este artigo busca traçar um olhar sobre as práticas de exceção na contemporaneidade. A partir do conceito de biopolítica, buscamos tramar diferentes perspectivas que se aproximam, tangenciam, elaboram e problematizam distintas práticas de exceção. Essa construção se tornou possível a partir de autores como Michel Foucault, Giorgio Agamben, Gilles Deleuze, Michael Hardt e Antonio Negri. 
Falar dessas práticas de exceção envolve falar sobre uma geografia matizada, marcada por muitas nuances e diversos territórios. Trata-se de visibilizar os muros mentais e materiais que se erguem entre as pessoas e as naçôes, nos quais a demarcação de leis (limites) pautadas na concepção de uma vida $z o e^{1}$ pode vir a configurar o despojamento da cidadania, da expressão, do respeito e dos direitos de determinados sujeitos. Cria-se, assim, um cenário capaz de conter campos de refugiados, campos de exilados, campos de deslocados, campos de detenção, enfim campos de exceçãa ${ }^{2}$ que reduzem os sujeitos à vida nua. Deste modo, tomaremos como emblema dessa questão o início da organização dos manicômios no Brasil e o campo de concentração nazista para pensarmos a constituição dessas fascistas práticas de exceção na modernidade e sua ruptura-continuidade no contemporâneo: "Não somente o fascismo histórico de Hitler e de Mussolini - que tão bem souberam mobilizar e utilizar o desejo das massas -, mas o fascismo que está em nós todos, que martela nossos espíritos e nossas condutas cotidianas" (Foucault, 1991: 82).

\section{BiopolítiCA E ESTADO DE EXCEÇÃO}

Michel Foucault ([1975] 1987; [1974-1975] 2001; [1994] 2001) aponta um refinamento das tecnologias de controle sobre os corpos entre os séculos XVII e XIX. Passa-se de uma configuração de poder soberano ([1994] 2001), no qual se incidia sobre a possibilidade ou não de vida dos súditos, para uma lógica disciplinar, na qual os modos de vida dos corpos dos súditos serão o objeto da intervenção. Um Estado que legisla sobre o "fazer viver": a biopolítica se refere, assim, ao homem vivo, enquanto as disciplinas se referiam aos corpos (Foucault, citado por Pelbart, 2003).

Quando analisa a transição das práticas diante da lepra e, posteriormente, da peste, Foucault ([1974-1975] 2001) irá delimitar uma transformação na prática para com os "anormais": do mero isolamento de anulação para o isolamento de reforma. Do simples processo de exclusão, através do isolamento, ao processo de inclusão, de cuidado. Passa-se a realizar um exame perpétuo do campo de regularidade da doença, operando sobre sua vida um poder que fabrica, observa, sabe. Constitui-se, desse modo, uma "arte de governar", em que mais do que operar sobre os corpos há um cuidado com os processos da vida.

Construíram-se, então, instituições para aqueles que de algum modo fugiam da normalidade ${ }^{3}$. Tais espaços circundados por muros ou grades serviam para a delimitação de conjuntos e subconjuntos de desviantes para que estes pudessem sofrer as devidas intervenções reformadoras de sua normalidade. Cria-se, então, 
uma estrutura classificatória que permite a imediata inteligibilização e intervenção sobre os corpos anormais.

Com isso, vê-se a construção do termo biopolítica - para Foucault ([1994] 2001) -, que vem a ser o engendramento de mecanismos de gestão de saúde, de higiene, de alimentação, de sexualidade, de natalidade, etc. São elementos que configuram a conjuntura social baseada em investimentos de controle de diversas dimensões da vida (Revel, 2005). A estatística formaliza os fenômenos da população em uma ciência do Estado, permitindo que o foco seja a espécie, e não somente a família e o indivíduo. Ainda que estes permaneçam sendo instrumentos da governamentalidade (Foucault, [1994] 2001) em sua arte de gerir a população a partir do detalhe, com uma arte do controle dos detalhes, a Disciplina (Foucault, [1975] 1987).

Estas práticas percorreram alguns séculos até atingirem seu ápice e o princípio de sua ruptura na metade do século XX. Com a crescente industrialização da sociedade e burocratização do Estado, cada vez mais se instituiu uma relação binária conflituosa entre indivíduo e sociedade, entre o singular e o geral. Tal binarismo advinha de uma série de práticas tutoras, de caráter progressista, que vinham cuidar do bem-estar do cidadão trabalhador para otimizar a capacidade de produção do mesmo.

A união da razão instrumental da ciência e dos dispositivos burocráticos do Estado, ambos absolutizados por uma pretensa neutralidade pura de princípios, desalinhou a gravata taciturna do burocrata em cruéis mecanismos para a construção de uma humanidade melhor. Deste racional regramento esquadrinhador e detalhado surgiram práticas que transbordavam aos esquadros, destas regras criaram-se exceçôes em acordo com as regras, como em uma dedução ao absurdo, na qual se leva um raciocínio ao limite da sanidade do mesmo: "Foi no momento mesmo em que o estado começava a praticar seus maiores massacres que ele começou a se preocupar com a saúde física e mental dos indivíduos” (Foucault, [1994] 2001: 318). Se na soberania era o Soberano mesmo que se apresentava como ponto transcendente ao Estado, na Governamentalidade será o próprio Estado, na imanência de seus dispositivos tecnoburocratas, que emergirá deste campo.

Pensando assim a articulação entre biopolítica e o campo de exceção na modernidade disciplinar, não devemos nos ater à questão de um tirano como ponto cego do esquadro das regras constituindo um Estado de exceção. Antes de ser um estado jurídico-político anormal assegurado por um soberano transcendente a este, será a transcendência construída pelo próprio Estado que irá assegurar a normalidade da exceção. 
O bem-comum, abstração construída acima das singularidades imanentes, sobrecodificando-as a partir do bom-senso e do senso-comum, é o que garante o status de legalidade às práticas que revertem os limites da legalidade. Posto que é pelo bem-comum que certas necessidades, certas urgências, despontam como justificativas do senso-comum através do bom-senso, em prol do bem-geral.

Assim, no decorrer do século XX, pôde-se assistir a um fenômeno paradoxal que foi bem definido como uma "guerra civil legal" (Schnur, citado por Agamben, 2004). Tome-se o caso do Estado nazista. Logo que tomou o poder, Hitler promulgou o Decreto para a proteção do povo e do Estado, no dia 28 de fevereiro, que suspendia os artigos da Constituição de Weimar relativos às liberdades individuais. O decreto nunca foi revogado, de modo que todo o Terceiro Reich pode ser considerado, do ponto de vista jurídico, como um estado de exceção que durou 12 anos. $\mathrm{O}$ estado de exceção constitui então, um "ponto de desequilíbrio entre direito público e fato político" (Saint-Bonnet, citado por Agamben, 2004: 11) que como a guerra civil, a insurreição e a resistência - se situa numa franja ambígua e incerta, na intersecção entre o jurídico e o político. Uma espécie de terra de ninguém, entre o direito público e o fato político, entre a ordem jurídica e a vida.

O totalitarismo moderno pode ser definido como a instauração, por meio do estado de exceção, de uma guerra civil legal que permite a eliminação física não só dos adversários políticos, mas também de categorias inteiras de cidadãos que, por qualquer razão, pareçam não-integráveis ao sistema político. $\mathrm{O}$ estado de exceção apresenta-se, nessa perspectiva, como um patamar de indeterminação entre democracia e absolutismo. A vida nua ${ }^{4}$ atinge sua máxima indeterminação (Agamben, 2004).

Se pensarmos na forma que assumiu o nazismo, sob o signo de uma biopolítica: é como se a vida nua do homo sacer ${ }^{5}$, em que se fundava o poder soberano, se tornasse agora explícita e imediatamente política ${ }^{6}$. Mas isto é, precisamente, o que caracteriza a viragem biopolítica da modernidade, isto é, a condição em que nos encontramos ainda hoje. O nazismo fará da vida nua do homo sacer, definida em termos biológicos e eugênicos, o lugar de uma decisão incessante sobre o valor e a ausência de valor, onde a biopolítica se transforma continuamente em tanatopolítica e o campo se torna conseqüentemente o espaço político (Agamben, citado por Vilela, 2000).

Todavia, Judith Revel (2005) nos coloca uma problemática a respeito da construção do termo biopolítica: caberia pensar a biopolítica como o "conjunto dos biopoderes" ou, na medida "em que o poder investiu a vida significa igualmente que a vida é um poder" que pode se localizar na própria vida - no trabalho, na linguagem, nos corpos, nos afetos, nos desejos, na sexualidade -, um "lugar de 
produção de subjetividade de desassujeitamento?" (Revel, 2005: 27). Essa questão tenciona uma dupla perspectiva da biopolítica.

\section{LUZ EM EXCESSO CEGA: O VIOLENTO DESPERTAR DA RAZÃO}

Deste modo, o judeu, o louco, o homossexual e o cigano foram postos no escopo da legalidade com sua inclusão em um campo de exceção ilegal, em função de um "bem-maior": a segurança da humanidade perante a ameaça da degradação de sua natureza, a garantia do seu melhor desenvolvimento. $\mathrm{O}$ desenvolvimento da sociedade moderna proveu à natureza os perigos de sua destruição e as tecnologias para seu aprimoramento.

Dentre tais tecnologias da reforma da natureza, vemos a instauração dos espaços manicomiais como um elemento fundamental neste jogo de esquadrinhar as cidades para sua melhor inteligibilidade e gestão. Os espaços urbanos no Brasil passaram a sofrer grandes modificações principalmente a partir do advento da República. Práticas sustentadas por um discurso que prega a modernização e a moralização do espaço urbano a um só tempo segundo uma utopia de civilidade: "a utopia da cidade perfeitamente governada" (Foucault, [1975] 1987: 164).

Largas avenidas, passeios públicos, iluminação moderna passam a ser tratados com o rigor formalizado de uma ciência de regulação dos fluxos. Ciência que classifica o louco, o pobre, o criminoso, o devasso, entre outros, e lhes reserva um lugar à parte das vias largas e retas, nas quais convivem os de bom tom: um escaninho etiquetado com escárnio e ordenado para torná-los previsíveis, controláveis, inofensivos.

O isolamento classificatório, anulador e reformador, destas instituições disciplinares que esquadrinharam as cidades baseia-se também em estratégias biopolíticas pelo bem-maior, assim como os campos de concentração e sua anulação radical da diferença. No caso específico da loucura, além do medo para com a diferença mesma e seu contágio pestilento, moral e biológico, vemos, na justificativa das práticas de exceção, para além da garantia do bem geral, a busca do bem particular do insano. Trata-se de protegê-lo de si, alienando-o dos direitos perante os demais e para si. Um sujeito jurídica, política e ontologicamente alienado. Como sintetiza Teixeira Brandão, auto-intitulado o Pinel brasileiro, no início do século XX: "o Estado deve ter poder de seqüestrar o louco, aliená-lo de seus direitos, em nome da defesa coletiva e da liberdade individual, contanto que seja assessorado pela psiquiatria” (Machado, citado por Wadi, 2000: 669).

Vemos claramente neste discurso a articulação entre a ciência do Estado, a burocracia e a ciência da saúde mental, a psiquiatria, colaborando na criação de 
alternativas de exceção para salvar uma ontologia de exceção: o louco. Erigemse, então, palácios humanistas para a reforma da humanidade. Deste modo, torna-se o hospício um ícone benfazejo da humanidade civilizada e da benevolência cristã 7 .

A "lei" permitiu, então, que fossem construídos espaços para acolher e disciplinar a "loucura". O ato de interdição, através de amparo legal e justificativa sociopolítica, passou a ser posto em prática, os loucos, por sua suposta periculosidade para si e os outros, eram sentenciados à reclusão e intervenção "terapêutica”. Assim, sendo o próprio hospital constituído como lugar de asilamento e isolamento, tornou-se um lugar de inclusão (ao aparelho normativo) e exclusão (social).

Assim, podemos tomar tanto o manicômio como os atrozes campos nazistas enquanto campos de exceção, que subtraem os direitos políticos, subjugando os ali incluídos-excluídos por uma outra lei, saber e prática. No campo ocorre o despojamento de todo estatuto político da vida, a lei aprisiona corpos destituídos de seus direitos, reduzindo-os a uma condição de mero vivente.

Esses espaços apenas expõem uma política de destruição programada do outro sob uma geografia de morte onde o corpo se afigura, por um lado, como efeito-objecto da localização e do desenvolvimento do poder e, por outro lado, como um dos elementos fundamentais dos jogos de poder e de verdade (Vilela, 2000: 39).

O nazismo fez da decisão sobre a vida nua o critério político supremo. Segundo Antelme (citado por Agamben, 2002), de fato, aquilo que os campos ensinaram a quem os habitava era justamente que colocar em questão a qualidade de homem provocava uma reivindicação quase biológica do pertencimento à espécie humana.

No caso dos manicômios, os corpos são submetidos à "proteção terapêutica" sob a custódia disciplinar da ciência. Nos campos de concentração nazistas, tínhamos a chamada Schutzhaft (custódia protetiva), que suspendia os artigos da constituição e seus direitos, deixando os prisioneiros submetidos aos poderes de um soberano. Através das justificativas da ciência, da política e dos direitos, esses campos de exceção foram criados. E lá homens foram depositados em nome de uma razão adormecida. $\mathrm{O}$ sono da razão ${ }^{8}$ produz delirantes sonhos soberanos que arrastam "prisioneiros" em reais pesadelos povoados por monstros.

Os campos de concentração mataram no ímpeto de construir um novo homem sob o qual se fizessem de direito os direitos do Homem direito. Tentativa radical de tornar realidade a igualdade entre os homens, permitindo a universalização dos direitos entre iguais a partir de práticas eugênicas de otimização 
da natureza humana: propondo-se a atualizar uma humana natureza humana. Como movimento humanista, o nazifascismo se utilizava da razão científica instrumental maturada em barris burocratas durante a formação dos grandes Estados modernos. Do mesmo modo, também foi um ímpeto humanista, progressista e cientificista, por parte do Estado, que multiplicou, ampliou e otimizou os espaços manicomiais no Brasil, principalmente a partir da República.

Os esforços de tal empreitada civilizatória findaram por cansar-se, alargando os horizontes que delimitavam a identidade do Homem: as instituições de fechamento, classificação e reforma entraram em crise; o Estado em sua transcendência entrou em crise; a família em sua eficácia docilizadora entrou em crise; etc. Os esquadros disciplinares e biopolíticos que delimitavam a modernidade começaram a se esbarroar diante de uma infiltração contemporânea.

Nas práticas características da modernidade a exceção se pretendia isolada em espaços cercados, não somente para que os subjugados à exceção não escapem desta, mas também para que o próprio modo de exceção não escape destes limites, se infiltrando no campo social, diluindo-se na regra de modo a não se distinguir mais desta. No entanto, principalmente a partir da segunda metade do século XX, os muros e grades que definiam binariamente a relação do campo de exceção institucional com o seu entorno tornam-se cada dia mais porosos, corroídos pela crise que afligiu as instituições ordenadoras de molaridades.

\section{Microfascismos EM NÓS}

Ao diluir sua transcendência, o Estado passou não mais a ordenar o campo de imanência, mas sim ser ordenado pelo campo do capital. Um novo conceito de biopolítica surge neste novo contexto: a tomada da vida pelo capital em suas entranhas (Hardt \& Negri, 2004). Não apenas o corpo é alvo de práticas cooptadoras, como também os afetos, os pensamentos, a criatividade, a imaginação e outros modos da alma humana são privatizados em prol de uma produção biopolítica: é a vida mesma que se torna objeto de produção no capitalismo tardio do espetáculo, consumo e trabalho intelectual.

Assim, os medos molares e as grandes paranóias, ordenados por ressonâncias centrais que lhes dão o feitio de conflitos binários dialéticos, os quais justificam, por sua vez, a criação de espaços fechados e isolados de exceção, passam a ceder gradativamente sua proeminência, nos arranjos de força contemporâneos, para uma "onicrise" (Hardt \& Negri, 2004), sem lugar ou direção definidos, categorias ou dinâmicas molares claras. A paranóia com relação a um povo, raça, nação se dilui crescentemente em uma série de pequenas paranóias sem 
direção definida que constituem uma multiplicidade nebulosa de inimigos ocultos no cotidiano. "Em lugar do grande medo paranóico, encontramo-nos presos por mil monomaniazinhas, evidências e clarezas que jorram de cada buraco negro e que não fazem mais sistema e sim rumor e zumbido" (Deleuze \& Guattari, 1996: 110).

A transformação nestas linhas que asseguravam as condições de possibilidade a um determinado arranjo de campo de exceção dá progressivamente corpo a outras práticas de exceção para além das já relatadas. As práticas de urgência, de sítio, de exceção tornam-se cotidianas, aquém de um Estado que lhes dê suporte. A exceção cotidiana vem dar conta de uma constante situação de urgência que se incorpora aos hábitos diários, sendo esta a fonte da necessidade que rompe com o sistema legal instaurando a exceção (Agamben, 2004). Isso implica em uma mudança no referencial da dinâmica da exceção, na qual o sujeito mesmo, e não um agente externo, irá sustentá-la. Ao invés da disciplinar dinâmica de uma formação coercitiva para uma posterior produção vigiada, vemos a própria auto-inserção na rede de consumo-produção como incitadora de uma participação nas práticas de exceção.

Deste modo, o sujeito mesmo poderá se infligir um microestado de exceção, privando-se, por exemplo, do direito sobre a circulação no espaço público, isolando-se em ilhas privativas em busca de segurança, independente dos custos desta para sua vida social, ou, ainda, pode prescindir dos seus direitos trabalhistas criando um campo de exceção aos mesmos para si em função da busca de uma conduta pró-ativa e empreendedora tomada como necessária na habitual urgência contemporânea dos resultados. Assim, constituem-se como modulação comum destes microfascismos cotidianos a distância e o isolamento tolerantes, que anulam a diferença ao circunscreverem os próprios hábitos com estratégias de evitação do outro, do heterogêneo. Pedestre que apenas pedra est ao passante, nada mais que um vulto sem qualidades, vida nua na calçada.

Do mesmo modo, as estratégias da Sociedade Disciplinar para com os loucos se diluem, esbarroam-se e se espalham com o vento pela cidade, constituindo outras práticas para com os antigos internos (Costa, 2007). Assim, de um espaço fechado estático e despersonalizado, passam a fechar-se em movimentos, circuitos fechados que não fazem rede nos fluxos da cidade, ou ainda fecham-se em grades privadas e mediações midiáticas, cerceando-se a um convívio que se resume aos personagens usuais de seus trajetos fechados: CAPS, casa, supermercado, casa. Os profissionais de saúde mental, então, plenos de boa vontade na proteção da vida alheia, pedagogicamente incutem os duros cristais das microparanóias que ordenam nossa urbanidade nestes músculos insanos, tornando-os plasticamente rígi- 
dos: "não fale com estranhos", "tranque sempre a porta", "não fique zanzando por aî", "não traga ninguém para casa", etc. Impedindo que certas operações de paradoxalização dos regimes espaciais contemporâneos, como a abertura das fronteiras da célula privativa mínima e o uso do espaço de passagem para o encontro, possam ser operados pelo louco em sua experimentação dos modos urbanos (Costa, 2007).

Outra variante deste agenciamento entre práticas de exceção e loucura no contemporâneo se dá na diluição dispersiva de outro elemento disciplinar de uma prática para com o insano: a patologização.

$\mathrm{Na}$ contemporaneidade, em conjunto com a diluição moduladora das identidades em geral, vemos a dispersão do estado de exceção "patologia", o qual deixa de ter contornos definidos e passa a infiltrar-se em todos os âmbitos da vida: tudo torna-se objeto de patologização e a patologia é agora a constante na vida cotidiana das pessoas. Um campo nebuloso de patologização generalizada foi criado por diversos conceitos inespecíficos em sua definição, como o de stress $^{9}$, e uma variedade de novas síndromes que se multiplicam a cada dia, somadas ao uso inespecífico de outros conceitos psiquiátricos, como depressão, transtorno de ansiedade, déficit de atenção e hiperatividade, entre outros.

Felix Guattari (1981), a propósito de pensar as lutas de classes, alerta que o "inimigo infiltrou-se por toda parte" ${ }^{10}$. Como lutar com esse inimigo é uma questão que pulsa a cada instante em que nos debruçamos em pensar sobre a biopolítica e as práticas de exceção produzidas no contemporâneo, que estão sob a égide do paradigma do Campo, como denomina Giorgio Agamben (2002, 2004). Tomamos, como exemplo, o alerta inflamado que Guattari elabora ao dizer que já não cabe falar de uma classe operária que se insurge frente a uma delimitada identidade do inimigo. E isso nos parece pertinente, uma vez que como fazer para lutar contra as práticas de exceção? Quem são seus agentes? O inimigo já não está mais em uma exterioridade a nós. Compartilhamos de que estamos a todo instante também gerindo, produzindo, multiplicando práticas de exceção. Certamente que não se enquadrariam hoje somente nos emblemáticos exemplos que trouxemos sobre o campo de concentração, nem aos manicômios, mas que, disseminadas em práticas cotidianas, operam com suas muitas facetas. Como o microfacismo opera em nós quando um louco, circulando em um ônibus ${ }^{11}$, passa, por exemplo, a falar sozinho?

Assim, chamaremos de microfascismos as práticas de exceção que concernem ao âmbito do micropolítico, práticas que habitam nossos pensamentos, nossas atitudes, nossos corpos. Que se infiltram por toda vida, não mais somente em um nível totalitário, definido, macro e visível, mas no entre, na invisibilidade, nas pequenas açôes cotidianas. Estando o fascismo em nós, como um estratégico ad- 
versário, com o qual temos que nos deparar a todo instante da vida ${ }^{12}$, caberia então pensarmo-nos em uma perspectiva ética.

Isso pois passamos a uma dimensão, apontada por Felix Guattari (1981), em que se trata de operações micropolíticas, que agem, multiplicam-se fragmentariamente em nós. "Coube a Deleuze explicitar que ao poder sobre a vida deveria responder o poder da vida, a potência 'política' da vida na medida em que ela faz variar suas formas e, acrescentaria Guattari, reinventa suas coordenadas de enunciação” (Pelbart, 2003: 25).

\section{DeClaraÇÃo dos direitos da IMANÊNCIA PARA ALÉM DO HoMEM}

Há que se compreender de que vida se fala quando definimos a vida como bem maior a ser protegido pela sociedade. Como vimos anteriormente, havia a vida de direito, normal, e a vida nua, sem quaisquer qualidades visíveis aos disciplinados olhos modernos da biopolítica estatal. O Homem Universal da Declaração Universal dos Direitos do Homem é ainda uma abstração que paira por sobre a paradoxal vida imanente, furtando-se de soslaio da sua impossibilidade de generalização com a criação dos direitos de uma entidade inexistente: o Homem Universal. Deste modo, criou-se na década de 1940 uma série de princípios fundamentais para a regulação das relações entre as nações, entre a nação e seus grupos e entre os grupos de cada nação. Tal prescrição baseia-se em uma realidade geral e uma idéia geral de justiça, não se atendo de forma plástica aos contextos problemáticos e suas singularidades. Reproduz, assim, de certo modo, a ação do bomsenso e seu juízo fundado sobre o senso-comum.

Dentre as variações que este campo abstrato prescritivo tomou, vemos uma forma universalista republicana e outra multicultural federativa. A primeira, baseada em uma idéia iluminista de uma nação e homem unos, iguais em sua constituição mesma, presa pela aculturação parcial dos pares em função de uma aproximação da norma esclarecida. Já no multiculturalismo, os direitos humanos adquirem a função de resguardar a segurança de segmentos distintos, protegendo, permitindo e até incentivando o mergulho destes em uma identidade considerada sua, sem a interferência dos demais segmentos sociais, étnicos, políticos ou culturais. Nesta versão dos direitos humanos, a abstração desprende-se da imagem do Homem Universal, espargindo-se em uma determinada quantidade de identidades segmentares deste, baseadas em critérios vários como etnia, cor da pele, condição sexual, entre outras.

Vivemos um movimento em que a concepção multicultural dos direitos humanos passa a ser cada vez mais influente, seguindo a lógica da diluição dispersiva 
das grandes entidades abstratas modernas em um cotidiano contemporâneo, sem que isso implique na dissolução das suas durezas e hegemonias. Certas forças, em nome da proteção de minorias, vêm criar couraças formais que distanciam a diferença da sociabilidade deste grupo. $\mathrm{O}$ medo indeterminado da onicrise atual gera um enclausuramento identitário, um distanciamento do outro, do díspar.

$\mathrm{O}$ respeito e a tolerância aliados às múltiplas abstrações identitárias tornamse indiferença à diferença, o engessamento politicamente correto que retira a capacidade de afecção das coisas docilizando-as em um esquadro de descrições frio. A distância respeitosa da cidadania (Rolnik, 1995) é a evitação da diferença sob a alegação do medo da impureza, do indeterminado e intempestivo. Assim, a única diferenciação aceita é a que desloca o sujeito de um conjunto a outro também já definido, em uma adiç̧ão de estilos que não provê abertura ao incerto e informe. A vida aqui, portanto, é protegida com mitos identitários que segmentam um plano de imanência, sendo a alteridade, a diferença, apagada por práticas várias, de evitação e docilização, tornando-as vida nua uma vez mais. Nua de qualidades do encontro, de possibilidades de afecção. Segundo este modo, os direitos humanos podem assegurar as práticas micropolíticas de exceção como as definimos antes: "ela ganhou o interior de cada um de nós com seu eu, com seu ideal de status que acreditamos ter que adotar para nós mesmos" (Guattari, 1981: 15).

Microfacismos em nós - práticas de exceção no contemporâneo - nos remete ao hoje de nossas atitudes, não se trata de nos refugiarmos em algum paraíso pretérito ou futuro, mas estarmos atentos a nossa dimensão ética. Tomar a vida a partir de um referencial da imanência poderia ser um modo para lidar com as nossas práticas de exceção do cotidiano. Uma espécie de escuta as difere, a afirmação do devir que nos motiva a agir diferentemente a cada encontro, em direção a uma luta constante contra as forças que aprisionam a vida.

Arquitetado sob a vertente espinosista, Gilles Deleuze (2002) aponta duas maneiras simultâneas de o corpo ser definido: uma cinética, que trata das infinitas partículas, com suas velocidades, lentidôes, movimentos e repouso; e outra, dinâmica, que trata dos estados intensivos, situados e compostos pelo poder de afetar e ser afetado. O conjunto dessas duas dimensões dos corpos é o que constitui o plano de imanência, que difere do plano teológico, o qual prima pela organização e desenvolvimento da vida, a transcendência.

Esta perspectiva traz um passo a mais ao que primeiramente entendíamos enquanto biopolítica e sua caracterização como "poder sobre a vida". Tratando-se de um plano em que as intensidades produzem arranjos, formas e enunciaçóes, cabe tomar a biopolítica como potência da vida. A operação biopolítica é tomada como uma extrapolação à dimensão da vida no sentido biológico, do controle dos 
corpos e das medidas políticas de gestão da população, dos estilos de vida e de todas as outras formas que vêm domesticar a vida segundo modulações préfabricadas e seguras.

Assim, para além dos fatos da vida, da vida nua, temos muitas qualificações para o viver. E é a partir disso que ampliamos a discussão até aqui apresentada para os demais aspectos da vida. Nas palavras de Peter Pelbart (2003): "vida concebida já como potência de variação de formas de vida” (Pelbart, 2003: 66).

Utilizando-nos desta concepção de vida imanente para ultrapassar as transcendências microfascistas dos fragmentários estados de exceção atuais, devemos problematizar o campo dos direitos humanos, não para sua dissolução, mas para abri-lo à indeterminação dos acontecimentos. Para tanto, devemos, como nos diz Deleuze no seu abecedário (Boutang, 1988-1989) ${ }^{13}$, pensar não na Justiça e suas categoriais abstrações redentoras da transcendência, mas, sim, na jurisprudência, onde está a vida imanente e sua variação ilimitada. Pensar o acontecimento singular, criar tessituras entre os casos, e não ordená-los a partir de um ponto comum, ou seccioná-los a partir de critérios segmentares.

Há que se pensar em uma micropolítica dos encontros, das conversas, das afetações enfim. Necessitamos pensar estratégias que vençam o medo da dissolução das identidades no contemporâneo sem apresentar como resposta o recrudescimento contra aquilo de impuro, de heterogêneo que tangencia nossos grupos. Pensar a jurisprudência é cartografar os acontecimentos em busca de pontos estratégicos de intervenção em prol da abertura a novos encontros e afecçôes, impedindo que as duras pérolas transcendentes inibam as potências biopolíticas do nosso cotidiano.

\section{REFERÊNCIAS BIBLIOGRÁFICAS}

Agamben, G. (2002). Homo Sacer: o poder soberano e a vida nua. Belo Horizonte: Editora UFMG. . (2004). Estado de exceção. São Paulo: Boitempo.

Costa, L. A. (2007). Brutas cidades sutis: espaço-tempo da diferença na contemporaneidade. Dissertação de Mestrado não publicada, Programa de Pós-Graduação em Psicologia Social e Institucional, Universidade Federal do Rio Grande do Sul, Porto Alegre, RS.

Deleuze, G. (2002). Espinosa: Filosofia prática. São Paulo: Escuta.

Deleuze, G. \& Guattari, F. (1996). Mil platôs, v. 3. São Paulo: Ed. 34.

Engelman, S. (2007). O campo de exceção e a vida nua. Em: Fonseca, T. M. G.; Engelman, S. \& Perrone, C. M. (2007). Rizomas da reforma psiquiátrica: a difícil reconciliação. Porto Alegre: Sulina/UFRGS. 
Foucault, M. (1974-1975). Os anormais: curso no Collège de France. São Paulo: Martins Fontes, 2001.

—. (1975). Vigiar e punir: nascimento da prisão. Petrópolis: Vozes, 1987.

(1991). Anti-Édipo: uma introdução à vida não-fascista. Em: Escobar, C. H. Dossier Deleuze (pp. 81-84). Rio de Janeiro: Hólon Editorial.

-. (1994). Ditos \& escritos, v. IV. Rio de Janeiro: Forense Universitária, 2001.

Guattari, F. (1981). A revolução molecular. São Paulo: Brasiliense.

Hardt, M. \& Negri, A. (2004). Império. Rio de Janeiro: Record.

Levi, P. (1988). É isto um homem. Rio de Janeiro: Rocco.

Pelbart, P. P. (2003). Vida capital: ensaios de biopolítica. São Paulo: Iluminuras.

Revel, J. (2005). Foucault, conceitos fundamentais. São Carlos: Claraluz.

Rolnik, S. (1995). À sombra da cidadania: alteridade, homem da ética e reinvenção da democracia. Em: Magalhães, M. C. R. (org.). Na sombra da cidade (pp. 141-170). São Paulo: Escuta.

Schiavoni, A. G. da C. (1997). A institucionalização da loucura no Rio Grande do Sul: o hospício São Pedro e a faculdade de medicina... Dissertação de Mestrado não publicada, Programa de Pós-Graduação em História, Universidade Federal do Rio Grande do Sul, Porto Alegre, RS.

Vilela, E. (2000). Corpos inabitáveis: errância, filosofia e memória. Enrahonar, no 31, 3552.

Wadi, Y. M. (2000). Aos loucos, os médicos: a luta pela medicalização do hospício e construção da psiquiatria no Rio Grande do Sul. Hist. cienc. saúde, v. 6, no 3, 659-679.

\section{Notas}

1 Segundo Giorgio Agamben (2002) os gregos valiam-se de dois termos semântica e morfologicamente distintos: zoé, que exprimia o simples fato de viver comum a todos os seres vivos (animais, homens ou deuses), e bios, que indicava a forma ou maneira de viver própria de um indivíduo ou grupo.

2 Segundo Selda Engelman (2007), diante dos estudos sobre o Estado de Exceção de Agamben, os campos de exceção seriam os espaços que reduzem homens qualificados política, econômica e socialmente (bios) a puros viventes (zoés).

3 É fundamental ressaltar aqui a transformação no conceito de normalidade: de mera diferenciação de naturezas distintas, de seres ontologicamente diferentes, praticamente não pertencentes à mesma espécie, se passa a uma definição de normalidade pautada na variação a partir de uma norma. Assim, o anormal agora é o sujeito que por algum motivo sofreu em algum grau um deslocamento diante da moda de uma curva de distribuição normal, constituindo- 
se enquanto um desvio padrão a ser realocado nos parâmetros não-desviantes. De uma concepção de normalidade instransponível passou-se para outra que universaliza a possibilidade de normalização e o dever do estado e da humanidade para com a reforma destes anormais.

4 Vida nua: vidas indignas de serem vividas e que perderam suas qualidades de bem jurídico. Uma redução do ser humano de plenos direitos ao ser humano sem direitos.

5 Homo sacer ou homo sacro, na figura do direito sacro romano, seria aquele que "o povo julgou por um delito, e não é lícito sacrificá-lo, mas quem o matar não será condenado por homicídio" (Agamben, citado por Engelman, 2007: 61).

6 Giorgio Agamben (2002) diz que o que caracteriza a política moderna não é tanto a inclusão da zoé na pólis, em si antiguíssima, nem simplesmente o fato de que a vida como tal venha a ser um objeto eminente dos cálculos e das previsões do poder estatal; decisivo é, sobretudo, o fato de que, lado a lado com o processo pelo qual a exceção se torna em todos os lugares a regra, o espaço da vida nua, situado originalmente à margem do ordenamento, vem progressivamente a coincidir com o espaço político: exclusão e inclusão, externo e interno, bios e zoé, direito e fato entram em uma zona de irredutível indistinção.

7 "Se nada mais tivermos para mostrar aos estrangeiros que nos visitarem senão o Hospício de Alienados, mereceremos, por certo, os elogios a que temos direito, como um povo civilizado e humanitário" (Souza, citado por Schiavoni, 1994: 22).

8 "O sono da razão produz monstros", de Goya (1799): emblema do paradoxo em que a razão, como saber-fazer que ali se constitui, pode vir a tornar-se excesso. Disponível em: http:// es.wikipedia.org/wiki/El_sue\%C3\%B1o_de_la_raz\%C3\%B3n_produce_monstruos. Acessado em: 15/10/2008.

9 O stress constitui-se enquanto síndrome modelo do contemporâneo, sendo produto e produtor da constância da urgência cotidiana, do hábito de exceção que toma conta do dia-a-dia.

${ }^{10}$ Felix Guattari (1981) discute a diluição dos inimigos com quem lutar, uma vez que os mecanismos burocráticos e antidemocráticos operam também nos espaços em que se luta por condições mais democráticas de vida.

${ }^{11}$ É de se esperar que essas práticas de circulação venham a acontecer cada vez mais em nosso cotidiano, se tomarmos alguns afrouxamentos propostos pelo movimento da Reforma Psiquiátrica.

${ }^{12}$ A todo instante na vida nos traz a dimensão contemporânea em que vivemos, em que o paradoxo do presente se desfaz a todo instante, e um futuro que virá se anuncia.

${ }^{13}$ Ver o vídeo: Boutang, P.-A. (diretor) (1988-1989). L’Abécédaire de Gilles Deleuze, avec Claire Parnet.

Recebido em 07 de agosto de 2008 Aceito para publicação em 13 de outubro de 2008 